\title{
Improved Chromatographic Methods for Determination of Bioactive Compounds from Aloe vera Leaves
}

\author{
L. Azaroual, ${ }^{1}$ A. Liazid, ${ }^{1}$ G. F. Barbero, ${ }^{2}$ J. Brigui, ${ }^{1}$ M. Palma, ${ }^{2}$ and C. G. Barroso ${ }^{2}$ \\ ${ }^{1}$ Departement de Génie Chimique, Faculté des Sciences et Techniques, Université Abdelmalek Essâadi, \\ P.O. Box 416, Tanger, Morocco \\ ${ }^{2}$ Departamento de Química Analítica, Facultad de Ciencias, Universidad de Cádiz, Campus de Excelencia Internacional \\ Agroalimentario (ceiA3), P.O. Box 40, 11510 Puerto Real, Spain \\ Correspondence should be addressed to M. Palma, miguel.palma@uca.es
}

Received 7 August 2012; Accepted 24 September 2012

Academic Editors: G. K. Jayaprakasha and A. Vazquez

Copyright ( $\odot 2012$ L. Azaroual et al. This is an open access article distributed under the Creative Commons Attribution License, which permits unrestricted use, distribution, and reproduction in any medium, provided the original work is properly cited.

In this work three chromatographic methods were developed to reduce the total time of the analysis of main compounds in Aloe vera extracts. The first method was developed in a regular reverse phase chromatographic system using a particulate reverse phase C-18 column. Methods already published were used as a starting point for the development of the new method. All the compounds were separated in 32 minutes. The second method was developed in a regular reverse phase chromatographic system employing a monolithic type column. Using a $4.5 \mathrm{~mL} \mathrm{~min}^{-1}$ flow, the total time of analysis was reduced to 6 minutes with very similar resolution values. The third method was developed in an ultraperformance liquid chromatographic system, and the final time for the analysis of the phenolic compounds was reduced to 4 minutes. The analytical properties of the three chromatographic methods were compared for the main compounds in the chromatograms. Robustness of the three new methods was also checked with regard to the injection volume and the amount of methanol in the sample. A fast method ( $4 \mathrm{~min}$ ) is then available for bioactive compounds from Aloe vera determination.

\section{Introduction}

Aloe vera has long been used as a remedy in many cultures. Aloe preparations, including products based on both the gel and the leaf, are used, among other reasons, as laxatives, in creams for skin, in functional foods, and as treatment for a wide range of diseases [1].

Aloin is the main anthraquinone in aloe leaf, which occurs naturally as a mixture of two diastereoisomers aloin $\mathrm{A}$ and aloin $\mathrm{B}$. In addition to these compounds, other compounds including aloenin, aloenin $\mathrm{B}$, and isoaloesin have been related to the biological properties of Aloe vera extracts [2].

Among the most recent properties studied for these compounds, the effects of aloin derivatives against some human breast cancer cell lines [3] have been reported. Other activities found for these compounds include several antimicrobial properties [4] and some oxidant and antioxidant properties on free radical-induced DNA breaks [5].
There are several factors which can influence the levels of aloin derivatives in the leaves of aloe plants, including cultivar conditions, age of the plant, and the health conditions. Therefore, the starting material to obtain the extracts can show clear differences [6]. These variations in the composition of Aloe can result in related products with different chemical and physical properties. Therefore, analytical methods to determine the aloin amounts in different plant material and manufactured products are useful.

High-performance liquid chromatography (HPLC) is the usual technique for the determination of individual components in Aloe vera leaf extracts. There are already several examples of the use of HPLC for the analysis of aloin derivatives [7]. All of them have been developed using a particulate reverse phase column. ElSohly et al. [8] have developed methods using both liquid chromatography/mass spectrometry (HPLC-MS) and liquid chromatography/photodiode array detection (HPLC/PDA) for the determination of aloe 
emodin and aloin A in aloe-based products. Rebecca et al. [9] also developed methods based on HPLC-MS for the studies of the exudates of the plants. This method needs 65 minutes for the separation of aloins. Park et al. [10] also developed a HPLC-PDA method for the separation of aloins in $50 \mathrm{~min}$. Zahn et al. [11] developed a HPLC-PDA method for similar compounds found in Aloe ferox Miller.

Both monolithic columns and ultra performance liquid chromatography (UPLC) have been introduced as two ways to obtain shorter separation methods. No references were found in the literature regarding their applications for the separation of aloins. Several applications have been developed for chromatographic separation using monolithic columns (see [12] for a review) and UPLC systems (see [13] for a review).

In this work, three different separation methods have been developed and compared in order to achieve a separation method for aloin related compounds found in Aloe vera extracts. A classical particulate column as well as a monolithic column was used in the HPLC methods. Moreover a UPLC based method was also studied. Analytical properties of the three methods have been studied and compared.

\section{Experimental}

2.1. Chemicals and Solvents. Methanol (Merck, Darmstadt, Germany) used was HPLC grade. Ultra pure water was supplied by a Milli-Q water purifier system from Millipore (Milford, MA, USA). Aloin A was obtained from Sigma (St. Louis, MO, USA). Stock solutions were prepared in 50\% methanol in water $(\mathrm{v} / \mathrm{v})$ and stored at $-32^{\circ} \mathrm{C}$.

2.2. Samples. Leaves from Aloe vera (var. barbadensis) were obtained from plants cultivated under different conditions and from plants with ages ranging from 1 to more than 5 years old. They were supplied by IFAPA Centro de Chipiona (Junta de Andalucía, Spain). Leaves were lyophilized and then milled and homogenized in an Ultraturrax T-25 (Ika, Staufen, Germany) at $24000 \mathrm{rpm}$ for $3 \mathrm{~min}$.

2.3. Ultrasound-Assisted Extraction. Extractions were carried out in an ultrasonic bath (J. P. Selecta, Barcelona, Spain). The extractions were performed at constant temperature by means of a temperature controller coupled to the ultrasonic bath. The extracts were obtained using $0.5 \mathrm{~g}$ of lyophilized sample and $25 \mathrm{~mL}$ of $50 \%$ methanol in water (v/v). The extraction was run at $10^{\circ} \mathrm{C}$ for 10 minutes. All extracts were filtered through a $0.22 \mu \mathrm{m}$ nylon syringe filter (Millex$\mathrm{HN}$, Millipore, Bedford, MA, USA) before chromatographic analysis.

2.4. High-Performance Liquid Chromatography. For the HPLC methods, the analyses were carried out on a Dionex system (Dionex, Sunnyvale, CA, USA), consisting of an autosampler (ASI 100), pump (P680), chromatographic oven (TCC-100), and a photodiode array detector (PAD100). UV absorbance was monitored from 200 to $400 \mathrm{~nm}$. The
TABLE 1: Main operational characteristics of the chromatographic methods.

\begin{tabular}{llccc}
\hline & Column & $\begin{array}{c}\text { Flow } \\
(\mathrm{mL} / \mathrm{min})\end{array}$ & $\begin{array}{c}\text { Pressure } \\
(\mathrm{psi})\end{array}$ & $\begin{array}{c}\text { Injection } \\
\text { volume } \\
(\mu \mathrm{L})\end{array}$ \\
\hline HPLC/P & $\begin{array}{l}\text { Gemini } 150 * 3 \mathrm{~mm} \\
5 \mu \mathrm{m}(\text { Phenomenex })\end{array}$ & 0.5 & 2800 & 25 \\
\hline \multirow{5}{*}{ HPLC/M } & $\begin{array}{l}\text { Chromolith } \\
\text { performance RP-18e } \\
(100 \mathrm{~mm} \times 4.6 \mathrm{~mm}) \\
\text { monolithic column } \\
(\text { Merck })\end{array}$ & 4.5 & 2200 & 25 \\
\hline UPLC & $\begin{array}{l}\text { Acquity BEH C18 } \\
2.1 * 50 \mathrm{~mm} 1.7 \mu \mathrm{m} \\
(\text { Waters })\end{array}$ & 0.7 & 11000 & 1.5 \\
\hline
\end{tabular}

TABle 2: Elution methods for the three systems are specified. Solvent A: water/acetic acid $(98: 2)$; solvent B: methanol/acetic acid $(98: 2)$.

\begin{tabular}{lccccc}
\hline \multicolumn{2}{c}{ Particulate C-18 column } & \multicolumn{2}{c}{ Monolithic column } & \multicolumn{2}{c}{ UPLC system } \\
Time (min) & $\begin{array}{c}\text { Solvent B } \\
(\%)\end{array}$ & $\begin{array}{c}\text { Time } \\
(\min )\end{array}$ & $\begin{array}{c}\text { Solvent B } \\
(\%)\end{array}$ & $\begin{array}{c}\text { Time } \\
(\min )\end{array}$ & $\begin{array}{c}\text { Solvent B } \\
(\%)\end{array}$ \\
\hline 0 & 0 & 0 & 0 & 0 & 0 \\
5 & 30 & 2 & 32 & 2 & 15 \\
20 & 30 & 5 & 32 & 3 & 60 \\
30 & 50 & 8 & 40 & 4 & 60 \\
40 & 100 & 9 & 100 & 4.1 & 100 \\
\hline
\end{tabular}

software for the control of the equipment and data acquisition was Chromeleon version 6.60. For the HPLC/M method, the analyses were performed on a monolithic type column (Chromolith TH Performance RP-18e, $100 \times$ $4.6 \mathrm{~mm}$ i.d., Merck). For the HPLC/P method the analyses were performed on a Gemini $(150 \times 3 \mathrm{~mm}$ i.d., $5 \mu \mathrm{m})$ column (Phenomenex).

The UPLC analyses were carried out on an Acquity UPLC System (Waters, Milford, MA, USA) equipped with a Model 2996 PDA detector. The column $(100 \times 2.1 \mathrm{~mm}$ i.d., $1.7 \mu \mathrm{m})$ was filled with BEH C18 packing material (Waters). The column oven was thermostated at $25^{\circ} \mathrm{C}$.

Table 1 shows the main operational characteristics of the chromatographic methods. Elution methods for the three systems are specified in Table 2 . All of them used acidified water ( $2 \%$ acetic acid) as solvent $\mathrm{A}$ and acidified methanol ( $2 \%$ acetic acid) as solvent B. Table 3 shows the analytical properties of the calibration curves for Aloin A in the three chromatographic methods. Quantification was carried out by integration of the peak areas at $280 \mathrm{~nm}$ using the external standardization method.

2.5. Identification of Aloin Derivatives. Identification of aloins was achieved by comparison of retention times and UV spectra of separated compounds as well as by coelution with the only authentic standard available (aloin A). Additionally HPLC-MS analyses were also carried out. A Finnigan LCQ-coupled LC-MS system (Thermo Electron 
TABle 3: Analytical properties of the calibration curves $(n=9$, triplicate injections) for aloin $\mathrm{A}$ in the three chromatographic methods.

\begin{tabular}{lccc}
\hline & LOD $(\mathrm{mg} / \mathrm{L})$ & LOQ $(\mathrm{mg} / \mathrm{L})$ & $R^{2}$ \\
\hline HPLC/P & 3.0 & 9.9 & 0.9984 \\
HPLC/M & 10.0 & 33.2 & 0.9937 \\
UPLC & 6.6 & 22.2 & 0.9936 \\
\hline
\end{tabular}

TABLE 4: Repeatability and reproducibility of the developed methods.

\begin{tabular}{lccccc}
\hline & \multicolumn{5}{c}{ Compounds } \\
& 1 & 2 & 3 & 4 & 5 \\
\hline HPLC with particulate C-18 column & & & & & \\
RT (min) & 7.9 & 9.0 & 25.1 & 29.0 & 30.7 \\
RT (RSD, $n=12$, intraday) & 0.49 & 0.64 & 1.39 & 0.54 & 0.40 \\
RT (RSD, $n=18$, interday) & 0.38 & 0.49 & 1.12 & 0.43 & 0.32 \\
Area (RSD, $n=12$, intraday) & 5.73 & 6.37 & 5.70 & 5.74 & 5.19 \\
Area (RSD, $n=18$, interday) & 5.38 & 6.19 & 5.81 & 5.07 & 4.39 \\
Asymmetry & 1.98 & 0.94 & 1.20 & 1.36 & 0.80 \\
\hline HPLC with monolithic columns & & & & & \\
RT (min) & 1.38 & 1.86 & 3.98 & 4.41 & 4.86 \\
RT (RSD, $n=12$, intraday) & 1.18 & 0.61 & 0.38 & 0.62 & 0.71 \\
RT (RSD, $n=18$, interday) & 1.07 & 0.77 & 0.96 & 1.45 & 1.58 \\
Area (RSD, $n=12$, intraday) & 0.64 & 3.02 & 0.99 & 0.79 & 0.57 \\
Area (RSD, $n=18$, interday) & 1.17 & 3.79 & 1.78 & 1.85 & 2.00 \\
Asymmetry & 1.31 & 1.29 & 1.16 & 1.43 & 1.63 \\
\hline UPLC & & & & & \\
RT (min) & 1.24 & 1.86 & 3.40 & 3.63 & 3.81 \\
RT (RSD, $n=12$, intraday) & 0.13 & 0.07 & 0.04 & 0.06 & 0.07 \\
RT (RSD, $n=18$, interday) & 0.25 & 0.22 & 0.04 & 0.05 & 0.06 \\
Area (RSD, $n=12$, intraday) & 0.25 & 0.35 & 0.77 & 0.26 & 0.18 \\
Area (RSD, $n=18$, interday) & 0.63 & 0.82 & 0.77 & 0.28 & 1.28 \\
Asymmetry & 1.80 & 2.02 & 1.29 & 1.87 & 1.01 \\
\hline
\end{tabular}

Co., San José, CA, USA) was used for the HPLC-MS analyses of extracts. This equipment is fitted with a Spectra SYSTEM 2000 model gradient pump (Thermo Scientific, Waltham, MA, USA) and a mass detector (model LCQ), consisting of an electrospray interface and an ion trap mass analyzer. Xcalibur, version 1.2, was the software used for the control of the equipment, and the acquisition and treatment of data. The sample injection volume was $25 \mu \mathrm{L}$. Interface conditions: positive ionization, temperature of the capillary: $220^{\circ} \mathrm{C}$, spray voltage: $20 \mathrm{kV}$, capillary voltage: $-5 \mathrm{~V}$, sheath gas flow: 80 (arbitrary units), and auxiliary gas flow: 10 (arbitrary units). API-MS spectra were acquired in the $\mathrm{m} / \mathrm{z}$ range of $50-400$

The chromatographic method used was a gradient elution, using acidified water ( $2 \%$ acetic acid, solvent $A)$ and acidified methanol ( $2 \%$ acetic acid, solvent $\mathrm{B})$, at a flow rate of $0.2 \mathrm{~mL} / \mathrm{min}$. The gradient employed was as follows: $0 \mathrm{~min}$, $0 \% \mathrm{~B} ; 1 \mathrm{~min}, 0 \% \mathrm{~B} ; 5 \mathrm{~min}, 30 \% \mathrm{~B} ; 20 \mathrm{~min}, 30 \% \mathrm{~B} ; 30 \mathrm{~min}$, $50 \%$ B; 40 min, $100 \%$ B. A C-18 column (Luna $5 \mu \mathrm{m}, 150$
TABLE 5: Aloin A recovery $(n=3)$ in all three methods developed using different addition levels (20, 40, 60\%).

\begin{tabular}{lccc}
\hline \multirow{2}{*}{ Chromatographic method } & \multicolumn{3}{c}{ Level of addition } \\
& $20 \%$ & $40 \%$ & $60 \%$ \\
\hline HPLC/P & $102.3^{\mathrm{a}}$ & $103.1^{\mathrm{a}}$ & $102.4^{\mathrm{a}}$ \\
HPLC/M & $97.8^{\mathrm{a}}$ & $98.4^{\mathrm{a}}$ & $99.5^{\mathrm{a}}$ \\
UPLC & $100.7^{\mathrm{a}}$ & $107.7^{\mathrm{a}}$ & $119.6^{\mathrm{b}}$ \\
\hline
\end{tabular}

In the same column, means followed by different superscripts are statistically different $(P<0.05)$.

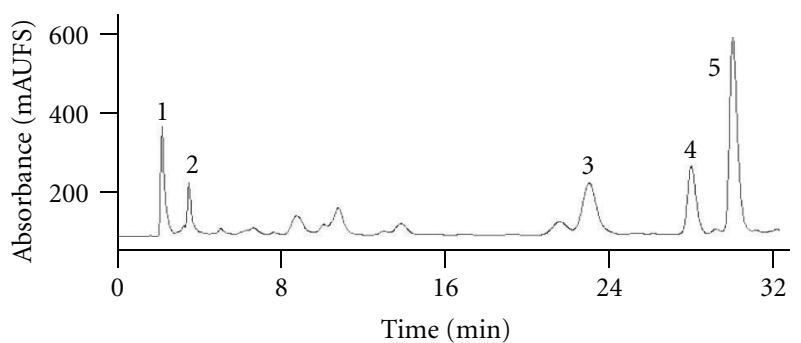

(a)

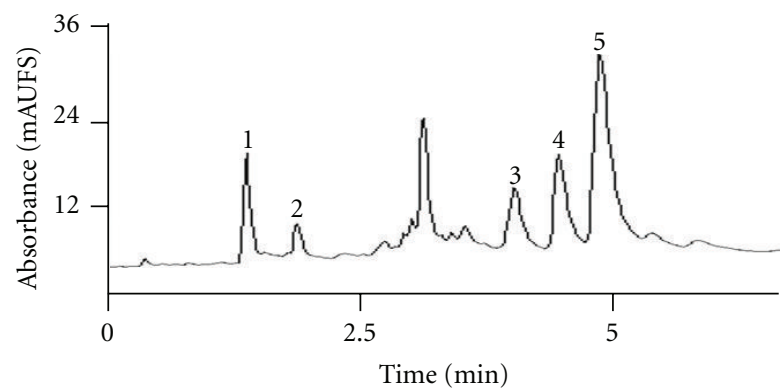

(b)

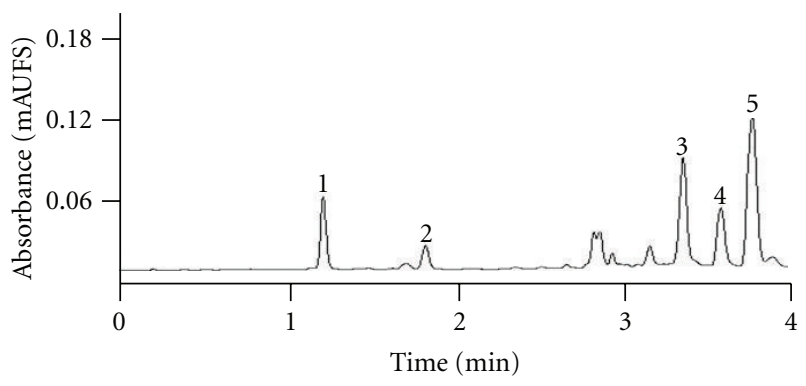

(c)

Figure 1: Typical chromatograms of an extract of Aloe vera leaves. (a) HPLC/P, (b) HPLC/M, (c) UPLC. Identification of aloins: 1: aloenin; 2: aloenin B; 3: isoaloesin; 4: aloin A; 5: aloin B.

$\times 3 \mathrm{~mm}$, Phenomenex) was used for the chromatographic separation.

2.6. Statistical Analysis. Results obtained during the method development were analyzed by one-way analysis of variance $(P<0.05)$. The ANOVA was performed using Excel 2003 software (Microsoft Co. Redmond, WA, USA) inbuilt features using a calculation table created with the same software. 


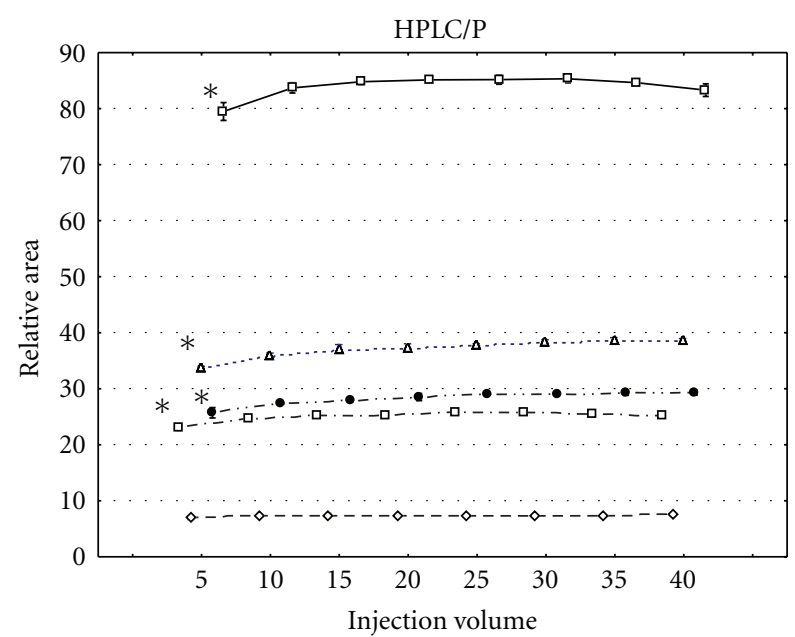

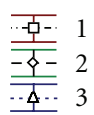

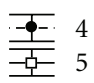

(a)

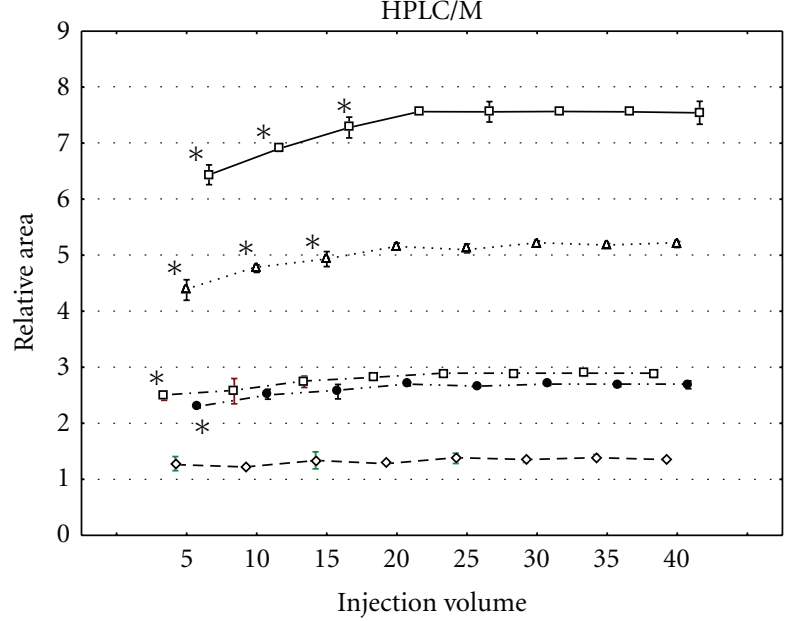

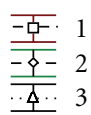

(b)

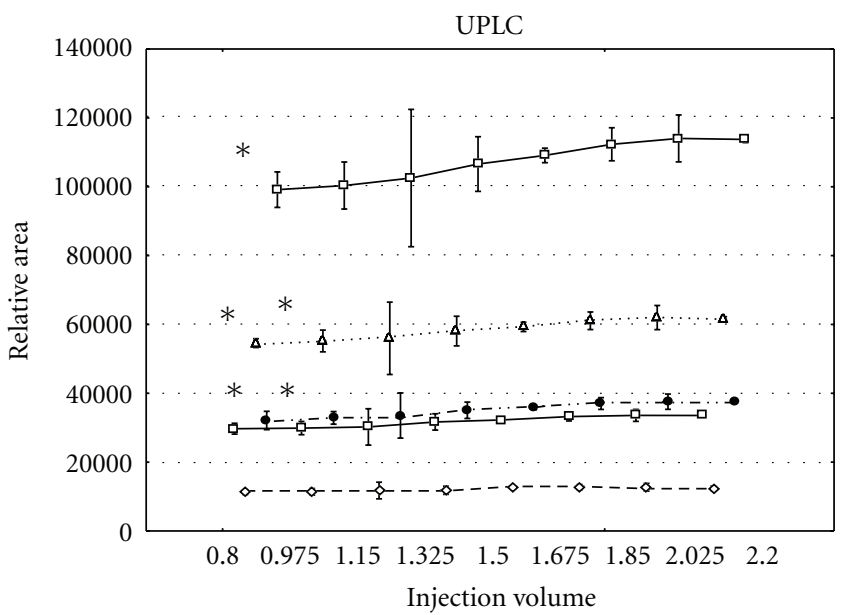

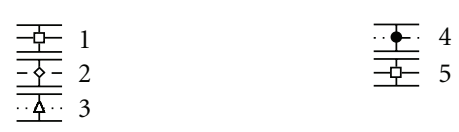

(c)

Figure 2: Values of chromatographic areas found in the three methods upon varying the injection volume. ${ }^{*}$ Statistically significant difference $(P<0.05)$ compared to the result of greatest area value of each chromatographic peak.

\section{Results and Discussion}

3.1. Comparison of Properties of the Methods Developed. Three separation methods were developed for the main compounds found in the extracts obtained from Aloe vera leaves. The typical resulting chromatograms of each method are shown in Figure 1. For the UPLC method, the retention time of the final compound was $3.81 \mathrm{~min}$, whilst in the case of the HPLC method with a monolithic column (HPLC/M) the time was $4.17 \mathrm{~min}$, and in the case of a particulate column (HPLC/P) it was $30.7 \mathrm{~min}$.

As it can be seen in Table 4, the repeatability and reproducibility of the retention times were similar in all cases, although somewhat greater in the case of UPLC. More specifically, in the UPLC case, the average error in terms of repeatability of the retention times was $0.07 \%$ whilst in the case of the HPLC/M method, it was $0.70 \%$ and in the case of HPLC/P it was $0.69 \%$. In terms of reproducibility (different samples and solvents) the average errors show similar values: UPLC 0.12\%; HPLC/M: 1.16\%; HPLC/C: 0.55\%. This means that the systems used in each of the three cases show a high reproducibility rate with respect to the separation conditions of these compounds. A comparison test was performed between the reproducibility and repeatability values of the three methods, with the findings showing that there were no significant differences. 


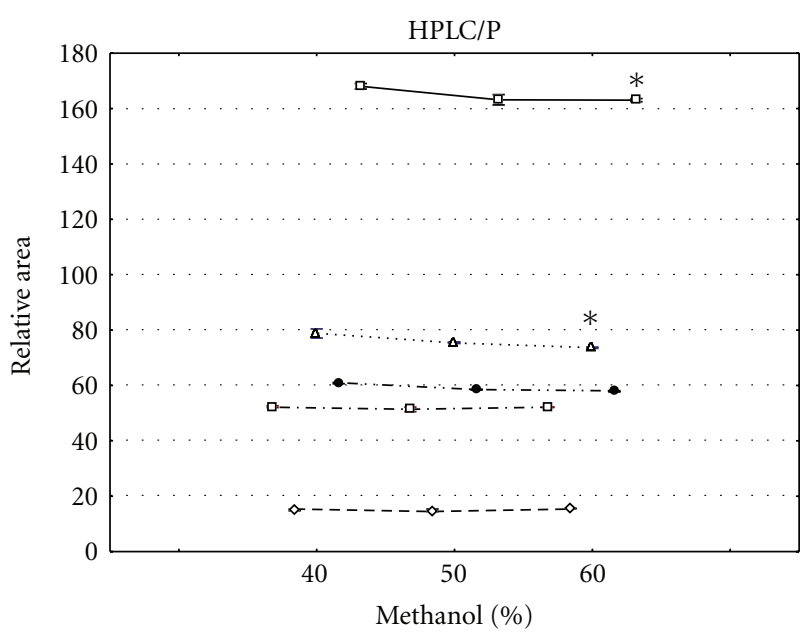

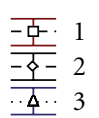

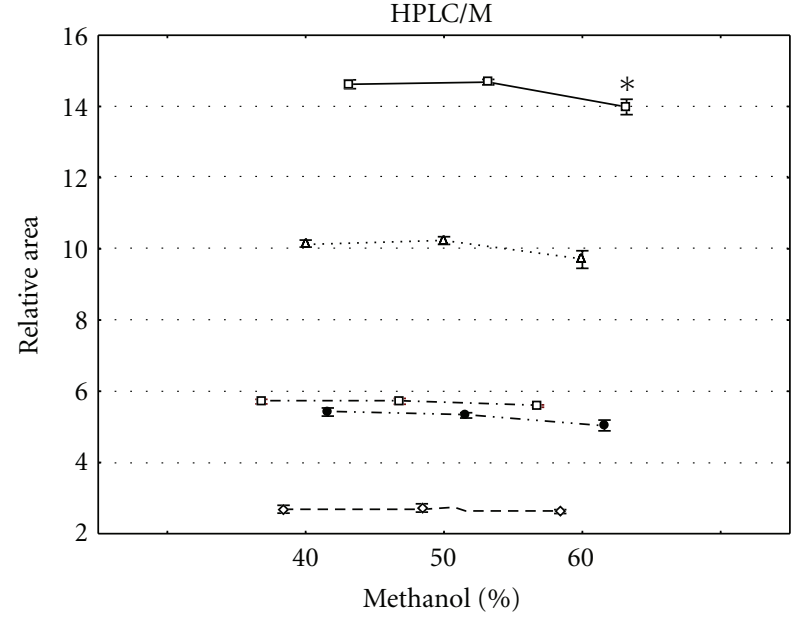

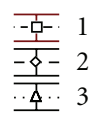

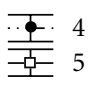

(b)

(a)

UPLC

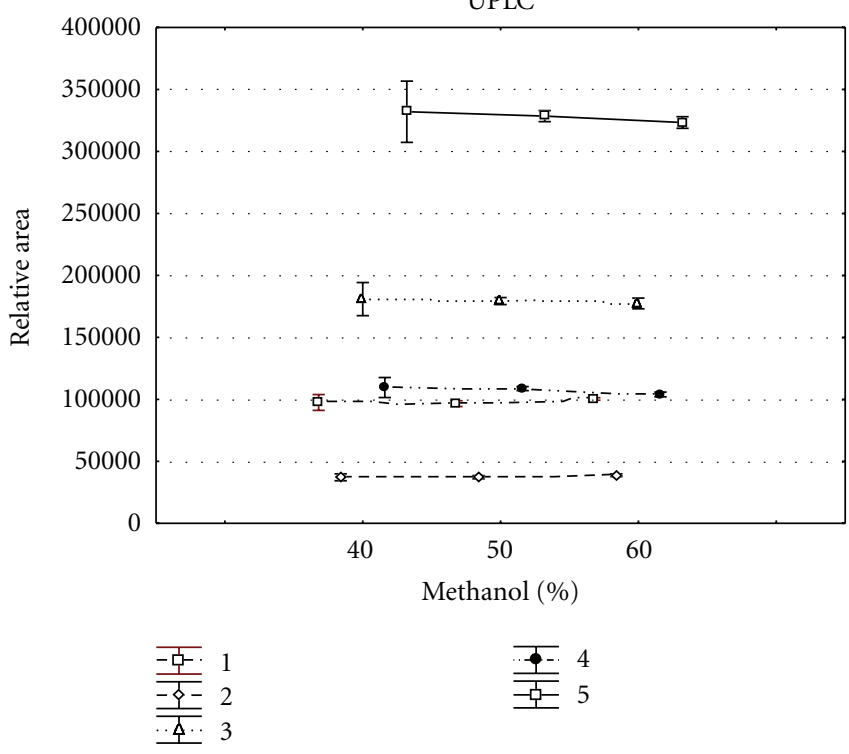

(c)

FIgURE 3: Values of chromatographic areas found in the three chromatographic methods upon varying the percentage of methanol in the sample between 40 and $60 \%$. ${ }^{*}$ Statistically significant difference $(P<0.05)$ compared to the result of the greatest area value of each chromatographic peak.

With reference to the chromatographic areas, various factors must be taken into account. First, the sample volumes used for injection were different in all three cases; second, the size of the measurement cells in each piece of equipment was different, and, third, the flow used in each system evaluated was different. These factors should have a direct effect on the limits of quantification in each method. As can be seen in Table 4, the errors are similar in the case of UPLC (0.63$1.28 \%$ for area) and in the case of HPLC/M (1.17-2.00\% for area), whilst they are higher in the case of HPLC/P (4.39$6.19 \%$ for area). Regarding the peak asymmetries, they were similar for all three methods developed, without significant statistical differences $(0.80-1.98 \%$ for HPLC/P, $1.16-1.63 \%$ for HPLC/M and $1.01-2.02 \%$ for UPL) $(P<0.05)$.

Recoveries were checked using the commercially available compound: aloin A. With additions ranging between 20 and $40 \%$ of the values found in the real sample, in each case recoveries were achieved that showed no significant 
difference $(P<0.05)$ between the three methods (Table 5) except for the greatest addition in the case of UPLC.

3.2. Robustness. In the application of the chromatographic methods to extracts from Aloe vera leaves, the injection volume may be variable, as a consequence of the different levels of analytes in different samples. Additionally, the composition of the extracts in respect of solvents may be also variable as different solvents can be used to run the extraction processes. For this reason, these two factors will be the ones that most clearly affect the analytical properties of the methods developed. Therefore, it was decided to determine the robustness of the three methods against the variations in these two factors.

In Figures 2 and 3 the results of the comparison between the results by area and by injection volume which were found for the different methods developed are shown. Each injection was performed three times on different days. It can be seen that the most reliable method against variations of the injection volumes was the HPLC/P method, for which significant differences were only found in the areas for the analyses using the lower injection volumes $(5 \mu \mathrm{L})$.

For the other methods these significant differences are produced especially in those compounds which have a longer residence time in the chromatographic system. Specifically, in the case of the method based on HPLC/M, the differences between the areas are significant up to injection volumes of $15 \mu \mathrm{L}$. For greater injection volumes no significant differences appear in the areas analysed. For the UPLC method, differences were found for volumes of up to $1.1 \mu \mathrm{L}$, from this volume onwards the differences were not significant.

In the case of robustness versus the composition of solvent in the sample, analyses were developed using percentages of methanol of between 40 and $60 \%$ in water, given the original proposal of using extraction solvents of 50/50 methanol and water for the extraction of these Aloe vera compounds. The results are shown in Figure 3 for all three methods developed. As with the previous case, the greatest variations are found in those compounds with a longer residence time in the chromatographic systems. In the case of the HPLC/M and HPLC/P systems some significant differences were found using between $40 \%$ and $60 \%$ methanol content in the sample. In the case of UPLC these differences did not appear. This parameter, therefore, turned out to have a lesser influence than the injection volume on the values of the chromatographic areas for aloins.

With these results, all three methods present operational conditions in which they are robust against variations in injection volumes and in the composition of the solvent, with none of the three methods showing a clear advantage, based on chromatographic parameters. However the UPLC method provided the fastest separation for these compounds.

\section{Conclusions}

The three methods developed allow for the quantification of the 5 aloin derivatives in Aloe vera extracts. The analytical properties of the three methods are found to be similar even though the method based on UPLC showed greater rates of reproducibility in chromatographic areas and retention times. In terms of robustness, with regard to injection volume it was the HPLC/P system which presented the best results, whilst for sample solvent all three methods showed similarly results. Based on time and residue generation, it was decided that the UPLC method should be used as a routine method for aloins analysis in Aloe vera extract samples, allowing for the detection of the different composition of plant leaves cultivated in different conditions and of different ages.

\section{Acknowledgments}

This work was carried out with the funding received for the project A/026575/09 supported by AECID. Centro IFAPA Chipiona (Junta de Andalucía) and especially Ms. Mariló Vela are more acknowledged gratefully for collecting and supplying the Aloe vera leaves.

\section{References}

[1] V. Steenkamp and M. J. Stewart, "Medicinal applications and toxicological activities of Aloe products," Pharmaceutical Biology, vol. 45, no. 5, pp. 411-420, 2007.

[2] D. Saccù, P. Bogoni, and G. Procida, "Aloe exudate: characterization by reversed phase HPLC and headspace GC-MS," Journal of Agricultural and Food Chemistry, vol. 49, no. 10, pp. 4526-4530, 2001.

[3] A. Y. Esmat, C. Tomasetto, and M. C. Rio, "Cytotoxicity of a natural anthraquinone (Aloin) against human breast cancer cell lines with and without ErbB-2-topoisomerase IIa coamplification," Cancer Biology and Therapy, vol. 5, no. 1, pp. 97-103, 2006.

[4] L. Kambizi, N. Sultana, and A. J. Afolayan, "Bioactive compounds isolated from Aloe ferox: a plant traditionally used for the treatment of sexually transmitted infections in the Eastern Cape, South Africa," Pharmaceutical Biology, vol. 42, no. 8, pp. 636-639, 2004.

[5] B. Tian and Y. Hua, "Concentration-dependence of prooxidant and antioxidant effects of aloin and aloe-emodin on DNA," Food Chemistry, vol. 91, no. 3, pp. 413-418, 2005.

[6] Y. Hu, J. Xu, and Q. Hu, "Evaluation of antioxidant potential of Aloe vera (Aloe barbadensis Miller) extracts," Journal of Agricultural and Food Chemistry, vol. 51, no. 26, pp. 77887791, 2003.

[7] N. Okamura, M. Asai, N. Hine, and A. Yagi, "Highperformance liquid chromatographic determination of phenolic compounds in Aloe species," Journal of Chromatography A, vol. 746, no. 2, pp. 225-231, 1996.

[8] M. A. ElSohly, W. Gul, B. Avula, and I. A. Khan, "Determination of the anthraquinones aloe-emodin and aloin-a by liquid chromatography with mass spectrometric and diode array detection," Journal of AOAC International, vol. 90, no. 1, pp. 28-42, 2007.

[9] W. Rebecca, O. Kayser, H. Hagels, K. H. Zessin, M. Madundo, and N. Gamba, "The phytochemical profile and identification of main phenolic compounds from the leaf exudate of Aloe secundiflora by high-performance liquid chromatographymass spectroscopy," Phytochemical Analysis, vol. 14, no. 2, pp. 83-86, 2003.

[10] M. K. Park, J. H. Park, N. Y. Kim et al., "Analysis of 13 phenolic compounds in aloe species by high performance 
liquid chromatography," Phytochemical Analysis, vol. 9, pp. 186-191, 1998.

[11] M. Zahn, T. Trinh, M. L. Jeong et al., "A reversed-phase high-performance liquid chromatographic method for the determination of Aloesin, Aloeresin A and anthraquinone in Aloe ferox," Phytochemical Analysis, vol. 19, no. 2, pp. 122-126, 2008.

[12] N. Wu and R. Thompson, "Fast and efficient separations using reversed phase liquid chromatography," Journal of Liquid Chromatography and Related Technologies, vol. 29, no. 7-8, pp. 949-988, 2006.

[13] N. Wu and A. M. Clausen, "Fundamental and practical aspects of ultrahigh pressure liquid chromatography for fast separations," Journal of Separation Science, vol. 30, no. 8, pp. 1167-1182, 2007. 


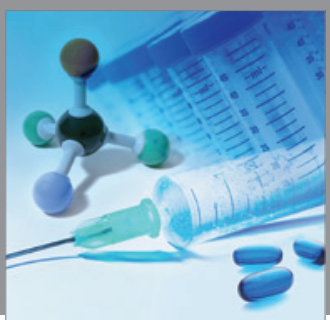

International Journal of

Medicinal Chemistry

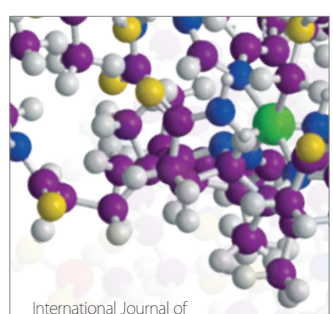

Carbohydrate Chemistry

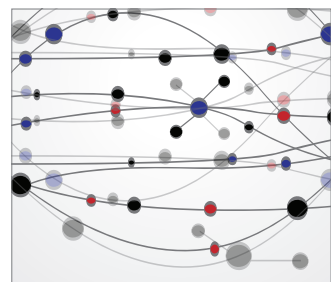

The Scientific World Journal
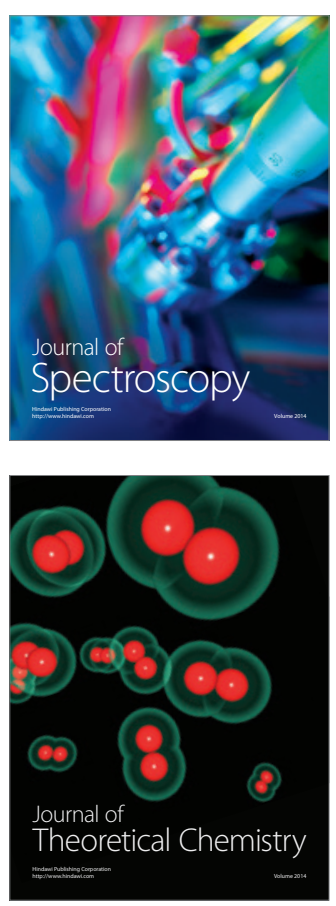
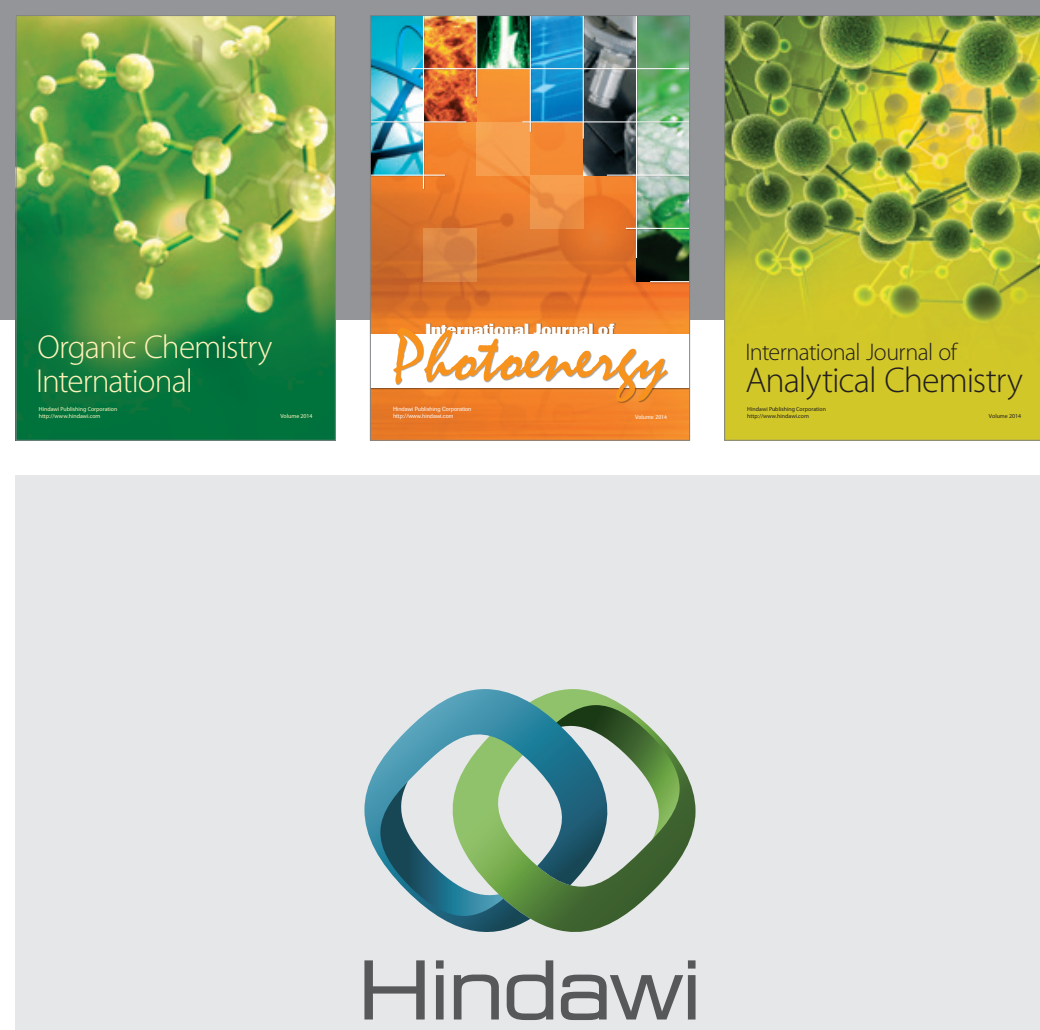

Submit your manuscripts at

http://www.hindawi.com
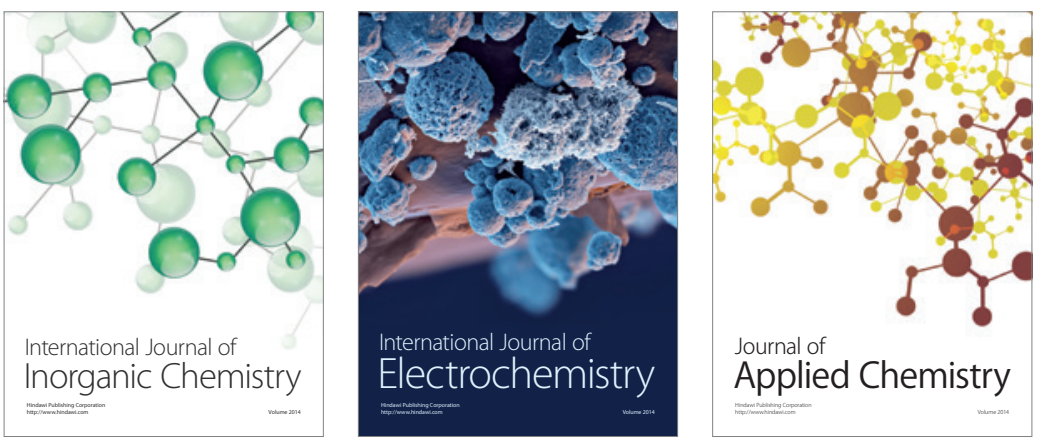

Journal of

Applied Chemistry
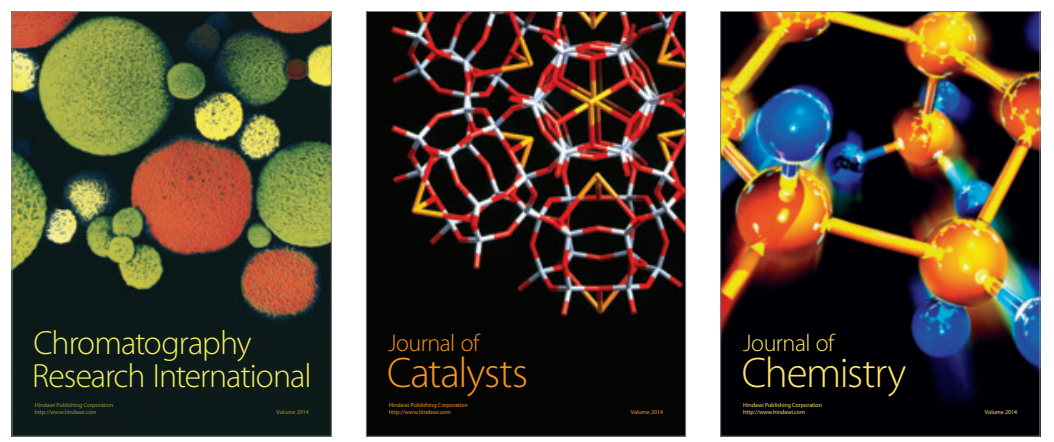
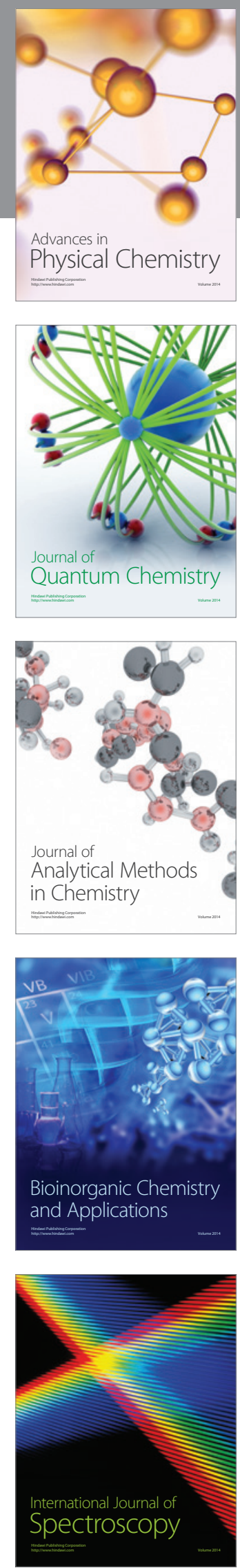